\title{
Kepemimpinan Transformasional Kepala PAUD untuk Meningkatkan Mutu Pendidik
}

\author{
Rosyida Nurul Anwar ${ }^{\circledR}$, Mulyadi², Achmad Khudori Soleh ${ }^{2}$ \\ Pendidikan Guru Pendidikan Anak Usia Dini, Universitas PGRI Madiun, Indonesia( ${ }^{(1)}$ \\ Manajemen Pendidikan Islam, Universitas Islam Negeri Maulana Malik Ibrahim Malang, \\ Indonesia(2) \\ DOI: $\underline{10.31004 / o b s e s i . v 6 i 4.1577}$
}

\begin{abstract}
Abstrak
Kepemimpinan transformasional merupakan gaya kepemimpinan melakukan perubahan untuk mencapai performa lebih baik. Tujuan penelitian ini untuk mengetahui bagaimana kepemimpinan transformasional kepala PAUD meningkatkan mutu pendidik. Metode penelitian menggunakan pendekatan kualitiatif dengan jenis studi kasus. Teknik pengumpulan data menggunakan observasi, wawancara, dan dokumentasi. Teknik analisis data yakni pengumpulan data, reduksi data, penyajian data, dan penarikan kesimpulan. Hasil penelitian menunjukkan bahwa kepemimpinan transformasional kepala PAUD untuk meningkatkan mutu pendidik melalui empat aspek yakni: Idealized influence yang ditunjukkan melalui keteladanan, kewibawaan, menjunjung nilai-nilai kemanusiaan, semangat tinggi dan keteguhan dalam menjalankan komitmen, etos kerja serta sikap religius. Inspirational motivation melalui perilaku yang memotivasi pendidik untuk terus berupaya meningkatkan kinerja dengan standar yang menjadi tugas pokok pendidik. Intellectual stimulation dengan kegiatan pengembangan wawasan pendidik seperti pelatihan dan pendidik, seminar, worksop. Individualized consideration melalui pemberian perhatian secara personal kepada pendidik dengan cara perenungan, pertimbangan dengan proses berfikir serta indentifikasi kebutuhan para pendidik.

Kata Kunci: kepemimpinan transformasional; kepala PAUD; mutu pendidik
\end{abstract}

\begin{abstract}
The transformational leadership is a leadership style to make changes to achieve better performance. This study aims to find out how the transformational leadership of the head of early childhood education to improve the quality of educators. The research method uses a qualitative approach with the type of case study. Data collection techniques using observation, interviews, and documentation. The results of the study indicate that the transformational leadership of the head of Early Childhood Education is to improve the quality of educators through four aspects, namely: Idealized influence, which is shown through example, authority, upholding human values, high spirit, and determination in carrying out commitments, work ethic, and religious attitudes. Inspirational motivation through behavior motivates educators to continue to strive to improve performance with standards that are the main tasks of educators. Intellectual stimulation with educators' insight development activities such as training and educators, seminars, workshops. Individualized consideration through giving personal attention to educators by way of reflection, consideration with the thought process and identification of educators' needs.
\end{abstract}

Keywords: transformational leadership; head of PAUD; quality of educators

Copyright (c) 2022 Rosyida Nurul Anwar, et al.

$\triangle$ Corresponding author:

Email Address: novitapgpaud@staff.uns.ac.id (Surakarta, Indonesia)

Received 23 June 2021, Accepted 27 July 2021, Published 4 February 2022 


\section{PENDAHULUAN}

Pendidikan Anak Usia Dini (PAUD) merupakan bentuk layanan pendidikan yang diberikan kepada anak sejak lahir hingga usia enam tahun (Kemendikbud, 2014). Pengembangan pribadi anak berkaitan dengan karakter, kemampuan fisik, kognitif, bahasa, seni, sosial emosional, spiritual, disiplin diri, konsep diri, maupun kemandirian menjadi dasar dalam PAUD (Mulyasa, 2012, p. 43); (Anwar \& Zaenullah, 2020). Aktor utama pada lembaga PAUD adalah pendidik (Smith, Hodson, \& Brown, 2013). Pendidik merupakan salah satu faktor yang mempengaruhi mutu dan keberhasilan pada lembaga pendidikan (Qomar, 2007, p. 23). Permasalahan mutu pendidik menjadi permasalahan serius dan memerlukan perhatian secara menyeluruh (Istiqomah, 2017). Pendidik adalah jabatan profesi, oleh karena itu pendidik harus professional karena ia selalu berada dan berinteraksi dengan peserta didik (Anwar \& Alfina, 2019a). Mutu akan tampak dalam hasil penilaian yang dilakukan oleh badan akreditasi nasional (Aqib, 2017). Pendidik yang bermutu akan menghasilkan generasi yang memiliki mutu/kualitas pula (Muhardi, 2005).

Permasalahan pendidik PAUD menjadi faktor belum tercapainya mutu. Diantara permasalah tersebut antara lain; Pertama, rendahnyanya gaji dan sedikitnya kompensasi yang diterima pendidik menjadi faktor pemicu belum terciptanya mutu pendidik (Boyd, 2013). Kedua, masih banyak guru yang senggan mengembangkan diri untuk menambah pengetahuan dan kompetensinya dalam mengajar (Yunus, 2017). Ketiga, masih banyaknya guru PAUD yang belum berkualifikasi, data pada Dirjen Pendidikan Anak Usia Dini Nonformal dan Informal (PAUDNI) Kementerian Pendidikan dan Kebudayaan, yang dikutip oleh Nofalia menyatakan bahwa sekiranya $80 \%$ guru PAUD belum berkualifikasi S1 atau D4 (Cikita, 2018). Maka dapat disimpulkan bahwa banyak pendidik PAUD yang mengajar tanpa bekal cukup serta belum menjadi pendidik professional, hal tersebut dapat terlihat dengan dominasi lulusan yang SMA sederajat. Berdasarkan uraian permasalahan tersebut, peningkatan mutu bisa terwujud dengan memperhatikan aspek-aspek tercapainya mutu pendidik.

Kepemimpinan kepala PAUD memiliki pengaruh besar terhadap meningkatnya mutu pendidik. Kepala PAUD sebagai pemimpin sekolah bertindak sebagai agen perubahan (Eyal \& Roth, 2011). Sejalan dengan Hoy dan Miske yang menyatakan bahwa salah satu faktor yang mempengaruhi mutu pendidik adalah kepemimpinan kepala sekolah (Hoy \& Miskey, 2013). Studi keberhasilan menunjukkan bahwa kepemimpinan kepala sekolah adalah seseorang yang menentukan titik pusat dan irama suatu sekolah (Nurhaya, 2017). Kepemimpinan transformasional merupakan gaya kepemimpinan dimana kepala sekolah mampu melakukan perubahan dalam diri individu untuk mencapai performa terbaik melalui kharisma, pemberian stimulus intelektual, motivasi, dan perhatian individu (Herminingsih, 2011).

Studi terdahulu mengemukaan bahwa kepemimpinan transformasional dapat meningkatkan mutu pendidik, diantaranya: Pertama, kepemimpinan transformasional berpengaruh signifikan terhadap kinerja pada berbagai aspek managerial dan menjadi mediator antara pemimpin dalam pengikutnya (Nguyen, Mia, Winata, \& Chong, 2016). Kedua kepemimpinan transformasional adalah anteseden penting dari kemampuan beradaptasi dan proaktif karyawan di tempat kerja (Wang, Demerouti, \& Le Blanc, 2017). Ketiga, kepemimpinan transformasional kepala sekolah dan kinerja guru yang memiliki hubungan signifikan terhadap mutu pendidikan (Maris, Komariah, \& Bakar, 2016). Keempat, kepemimpinann transformasional kepala sekolah berpengaruh signifikan terhadap mutu sekolah dan dapat diterima (Maris, Komariah, \& Abubakar, 2016).

Saat ini, eksistensi lembaga PAUD seperti jamur yang tumbuh di musim penghujan. Kota Madiun, pada tahun 2019/2020 tercatat memiliki 222 lembaga PAUD pada jenjang pendidikan formal, nonformal maupun informal. TK Islam Al Irsyad Madiun dan TK Islamiyah Rahmatan Lil'alamin Kota Madiun merupakan lembaga PAUD yang berhasil dalam mencapai mutu pendidik dibawah kepemimpinan transformasional kepala PAUD. Melalui 
kepemimpinan transformasional, pendidik PAUD dapat mencapai kinerja melebihi yang telah diharapkan pemimpin.

Kepemimpinan transformasional Kepala TK Islam Al Irsyad Madiun dan Kepala TK Islamiyah Rahmatan Lil'alamin memiliki sepak terjang yang memuaskan. Berdasarkan hasil pra penelitian dalam bentuk survey didapati adanya peningkatan dari berbagai hal disebabkan kepemimpinan trasnformasional kepala PAUD: Pertama, sekolah banyak memenangkan berbagai perlombaan yang dikuti pendidik dan peserta didik; Kedua, adanya peningkatan jumlah peserta didik setiap tahun. Ketiga, bertambahnya pendidik yang berkualifikasi, meningkatnya pendidik yang memiliki sertifikat pendidik. Keempat, pendidik di TK Islam Al Irsyad dan TK Islamiyah Rahmatan Lil'alamin mampu meningkatkan kemampuannya dalam berbagai kompetensi dengan adanya berbagai bentuk pengembangan dan pelatihan guru, kepala PAUD senantiasa memantau kinerja guru ditandai adanya rapat koordinasi dan rapat evaluasi yang diadakan di setiap pekannya. Peningkatan yang terjadi di TK Islam Al Irsyad Madiun dan TK Islamiyah Rahmatan Lil'alamin Kota Madiun tersebut sebagai bagian dari keberhasilan kepemimpinan transformasional kepala PAUD.

Gaya kepemimpinan kepala PAUD yang memikat nilai moral para pendidik dalam upaya meningkatkan kesadaran pendiidk untuk bergerak, memobilisasi energy serta merefrmasi lembaga PAUD disebut dengan kepemimpinan transformasional (Sumual, 2019). James McGregor Burns tahun 1979 merupakan pemikir pertama yang mengemukaan konsepsi kepemimpinan transformasional dengan istilah transformasional leadership yang kemudian dikembangkan oleh Bernard M. Bass pada tahun 1985. Teori kepemimpinan transformasional Bass sebagai sebuah upaya pemimpin mengubah nilai-nilai pribadi pengikut, mendukung visi dan tujuan organisasi dengan membina lingkungan di mana hubungan dapat terjalin dan dengan membangun iklim kepercayaan agar dapat mencapai visi yang telah ditetapkan (Bass, 1985, p. 3); (Bass, 1990, p. 20). Bass dan Avolio mengemukakan bahwa kepemimpinan transformasional mempunyai empat dimensi yaitu idealized Influence (kharisma), inspirational motivation (motivasi inspirasi), Intellectual stimulation (stimulasi intelektual), dan individualized consideration (perhatian individu) yang yang disebut Bass sebagai "the Four I's" (Bass \& Avolio, 1993).

Penelitian yang akan diangkat oleh peneliti memiliki keistimewaan dan perbedaan serta keunikan tersendiri dibandingkan pada penelitian sebelumnya. Penelitian terdahulu yang relevan dengan penelitian ini adalah sebagai berikut: Pertama, penelitian mengenai kepemimpinan transformasional kepala sekolah menghasilkan penelitian tentang nilai-nilai dan proses kepemimpinan transformasional kepala sekolah serta bagaimana kondisi model pemimpin visioner untuk menciptakan perubahan ke arah yang lebih baik (Hafidz, 2019). Penelitian Hafidz membahas mengenai kepemimpinan transformasional dengan menghasilkan nilai-nilai dari kepemimpinan transformasional akan tetapi belum mengarah dengan peningkatan mutu pendidik. Kedua, kepemimpinan transformasional kepala sekolah dalam mengimplementasikan pendidikan karakter yang menghasilkan tentang bagaimana memberikan teladan kepada bawahan, memberikan motivasi bawahan, memberikan stimulus intelektual kepada bawahan meliputi mampu menstimulus ide-ide keatif untuk memecahkan masalah; memberikan perhatian kepada individu dan memenuhi kebutuhan peserta didik untuk pengembangan dan peningkatan potensi akademik maupun non akademik (Brata, 2017). Penelitian tersebut belum menggarah pada bagaimana kepemimpinan transformasional kepala sekolah meningkatkan mutu pendidik. Ketiga, kepemimpinan transformasional memiliki pengaruh langsung terhadap kepuasan kerja (Kosasih, 2017). Penelitian ini membahas tentang kepuasan kerja karyawan/pendidik namun belum mengarah pada peningkatan mutu karyawan/pendidik.

Beberapa penelitian tersebut belum menyentuh ranah pada lembaga PAUD, dan belum mengkaji lebih dalam mengenai kepemimpinan transformasional untuk meningkatkan mutu pendidik. Tujuan penelitian ini adalah untuk mengetahui bagaimana kepemimpinan transformasional kepala TK Islam Al Irsyad dan TK Islamiyah Rahmatan Lil'alamin untuk 
meningkatkan mutu pendidik berdasarkan empat aspek yakni idealized Influence, inspirational motivation, Intellectual stimulation, dan individualized consideration. Penelitian ini diharapkan menjadi sumbangan pendidikan tentang konsep kepemimpinan transformasional kepala PAUD dalam meningkatkan mutu pendidik di lembaga PAUD.

\section{METODOLOGI}

Penelitian ini menggunakan pendekatan kualitiatif dengan jenis studi kasus yang berupaya memahami fenomena dibalik fenomena yang terjadis secara mendalam. Penelitian ini menggunakan rancangan multi kasus. Lokasi penelitian pada lembaga PAUD pada bentuk TK yakni di TK Islam Al Irsyad dan TK Islamiyah Rahmatan Lil'alamin yang berada pada Kota Madiun, Provinsi jawa Timur. Proses pemilihan informan menggunakan teknik purposing sampling yaitu peneliti memilih orang yang mengetahui secara jelas permasalahan yang diteliti. Informan pada penelitian ini adalah kepala PAUD, pembina, pendiri dan pengurus Yayasan, pendidik dan tenaga kependidikan, wali murid, serta stakeholder pada kedua lembaga lokasi penelitian.

Jenis data dalam penelitian ini dibedakan menjadi dua, yaitu data primer dan data sekunder. Data primer diperoleh dalam bentuk kata-kata atau ucapan lisan (verbal) dan perilaku dari informan yang berkaitan dengan kepemimpinan transformasional kepala PAUD dalam meningkatkan mutu pendidik. Data sekunder diperoleh dari dokumen-dokumen, fotofoto, dan benda-benda yang dapat digunakan sebagai pelengkap data primer.

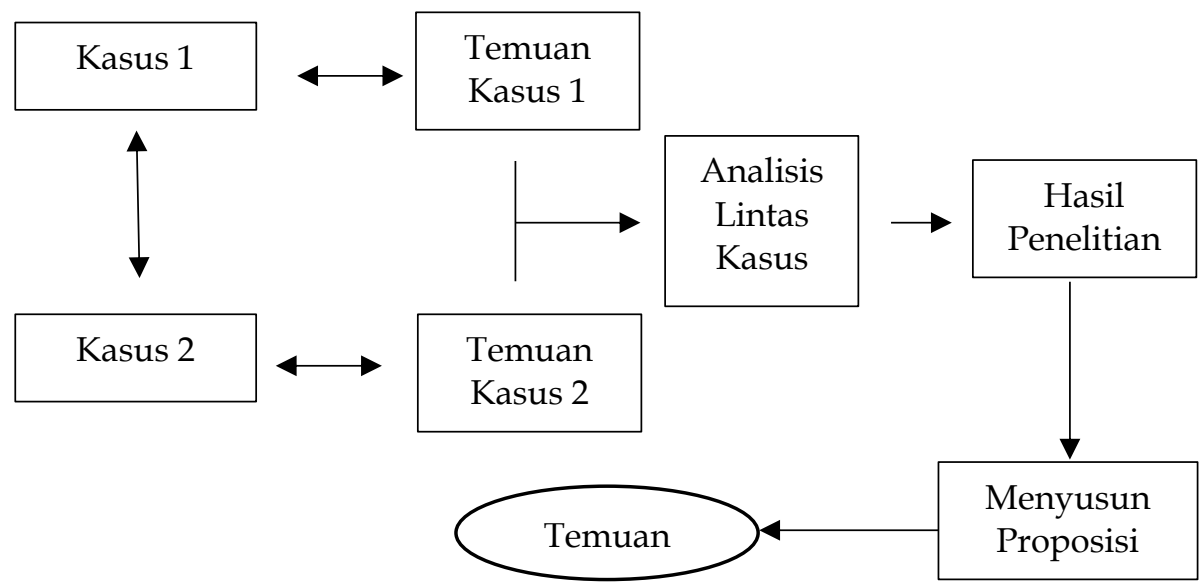

Gambar 1. Langkah-langkah Analisis Data Lintas Kasus

Teknik pengumpulan data menggunakan observasi partisipan, wawancara mendalam dan studi dokumentasi. Observasi dilakukan oleh peneliti dengan cara pengumpulan data berdasarkan observasi menggunakan mata, telinga, secara langsung tanpa melalui alat bantu yang berstandar atau disebut dengan istilah pengamatan. Observasi dilaksanakan dengan teknik participant observation, yaitu dilakukan dengan cara penelitian melibatkan diri atau berinteraksi pada kegiatan yang dilakukan oleh subyek penelitian dalam lingkungannya, selain itu juga mengumpulkan data secara sistematik dalam bentuk catatan lapangan. Wawancara dilakukan dengan peneliti melalui tahapan: Pertama, membuat kisi-kisi untuk mengembangkan kategori dan sub-kategori yang akan menggambarkan siapa orang yang tepat mengungkapkannya; Kedua, menetapkan informan kunci; Ketiga, membuat pedoman wawancara yang berisi pokok-pokok masalah yang akan menjadi bahan pembicaraan; Keempat, menghubungi dan melakukan perjanjian wawancara dan melangsungkan wawancara. Dokumentasi adalah foto, dokumen, dan bahan statistic. Metode dokumentasi digunakan untuk mengumpulkan data tertulis yang dapat memberikan keterangan data yang dibutuhkan, dapat dimanfaatkan untuk menguji, menafsirkan, dan meramalkan. 
Teknik analisis data penelitian mengacu pada model Miles dan Huberman yakni pengumpulan data, reduksi data, penyajian data, dan penarikan kesimpulan. Rancangan penelitian multi kasus dalam menganalisi data dilakukan dua tahap, yaitu analisis data kasus individu (individual case) dan analisi data lintas kasus (cross-case analysis). Langkah analisis data disajikan pada gambar 1.

\section{HASIL DAN PEMBAHASAN}

Berdasarkan hasil penelusuran yang telah dilakukan di TK Islam Al Irsyad dan TK Islamiyah Rahmatan Lil'alamin mengenai kepemimpinan trasnformasional kepala PAUD untuk meningkatkan mutu pendidik pada empat aspek kepemimpinan trasnformasional, maka didapatkan hasil penelitian sebagai berikut:

\section{Idealized Influence}

Berdasarkan hasil penelusuran peneliti, aspek idealized Influence yang ditunjukkan melalui kepemimpinan kepala PAUD untuk meningkatkna mutu pendidik melalui perilaku pemimpin berupa keteladanan dan mampu menularkan uswah dalam organisasi pendidikan, sehingga perilaku tersebut terlihat oleh pendidik. Perilaku kepala PAUD di TK Islam Al Irsyad dan TK Islamiyah Rahmatan Lil'alamin, sama-sama berupaya memberikan contoh baik nyata dengan harapan pendidik mencontoh keteladan tersebut.

Keteladanan Kepala TK Islam Al Irsyad yang sebelumnya bukan berasal dari sarjana PAUD atau yang relevan dengan PAUD namun telah mampu untuk mencapai syarat kualifikasi akademik pendidik PAUD dengan berkualifikasi S1 PAUD. Sedangkan keteladan yang tunjukkan Kepala TK Islamiyah Rahmatan Lil'alamin melalui pengembangan kompetensi melalui berbagi pendidikan dan pelatihan yang terus-menerus ditingkatkan dan dilakukan secara kontinu.

Hasil penelitian ini sesuai dengan peraturan yang menjadi standar kualifikasi akademik pendidik PAUD adalah berkualifikasi D-IV atau S1 dalam bidang PAUD dan kependidikan yang relevan dengan system PAUD atau psikologi dari program studi yang terakreditasi (Menteri Pendidikan dan Kebudayaan, 2014). Standar kualifikasi akademik adalah bagian dari syarat pendidik itu memiliki kualitas (Anwar \& Alfina, 2019b). Kepala TK Islam Al Irsyad menyadari bahwa kualifikasi akademik untuk pendidik PAUD sangat mempengaruhi pendidik dalam melakukan pembinaan, pengajaran dan pengembangan peserta didik. Selaras dalam Undang-undang guru dan dosen dalam Priansa bahwa seorang pendidik harus memiliki kualifikasi akademik dikarenakan pendidik adalah sebagai agen pembelajaran (Priansa, 2014, p. 111)

Hasil penelusuran lainnya mendapatkan bahwa kharisma pada kepemimpinan transformasional kepala PAUD untuk meningkatkan mutu pendidik dengan memberdayakan pendidik agar memiliki etos kerja tinggi. Etos kerja pada karakteristik kepemimpinan transformasional dengan menunjukkan produktivitas kerja melalui kemampuan memperoleh manfaat sebesar-besarnya dari sarana dan prasarana yang tersedia dengan menghasilkan output dan input yang optimal.

Temuan ini, sesuai dengan pandangan Sinamo dalam Saleh bahwa aspek etos kerja adalah seperangkat perilaku kerja positif yang berakar pada kesadaran yang kental, keyakinan yang fundamental, disertai komitmen yang total pada paradigma kerja integral (Saleh \& Utomo, 2018).

Al Qur' an dan Hadis tersebut menganjurkan kepada manusia, khususnya umat Islam agar memacu diri untuk bekerja keras dan berusaha semaksimal mungkin, dalam arti seorang muslim harus memiliki etos kerja tinggi sehingga dapat meraih sukses dan berhasil dalam menempuh kehidupan dunianya di samping kehidupan akheratnya. Pendapat Saifullah mengaitkan kerja dnegan agama, bahwa agama apat memberikan pengaruh positif terhadap etos kerja seseorang, manakala dapat memotivasi umatnya untuk meraih prestasi kerja yang tinggi, dan sebaliknya doktrin agama dapat memberikan pengaruh negatif (melemahkan etos 
kerja), manakala tidak mampu mendorong umatnya untuk meningkatkan etos kerjanya (Saifulloh, 2010).

Idealized Influence (kharisma) yang dimaknai sebagai kepribadian menarik dan penuh semangat dihasilkan oleh kepemimpinan kepala TK Islam Al Irsyad dan Kepala TK Islamiyah Rahmatan Lil'alamin. Hasil observasi dan wawancara didapati bahwa kedua kepala PAUD memiliki standar moral yakni berupaya bersikap dan berprilaku yang menjunjung nilai-nilai kemanusiaan. Sikap religius yang tunjukkan dari penampilan sebagai makhluk yang memiliki kepercayaan, berupaya menjalankan kewajiban Islam. Semangat tinggi dengan keteguhan menjalankan komitmen, etos kerja tinggi dan berupaya menjalankan visi misi sekolah yang dipimpinnya. Kepribadian yang dimunculkan dari kepemimpian kepala PAUD tersebut memberikan dampak positif pada pendidik PAUD.

Kepala TK Islam Al Irsyad dan Kepala TK Islamiyah Rahmatan Lil'alamin telah dinyatakan memiliki kharisma oleh pendidik di lembaga masing-masing. Berdasarkan hasil wawancara ditemukan bahwa pendidik mengakui kekharismaan kepala PAUD melalui keteguhan, tingkat rasa hormat yang menciptakan kesetiaan. Adanya pengakuan kharisma dari pendidik terhadap kepala PAUD sesuai dengan konsep Max Weber dalam buku yang ditulis Bass bahwa seorang pemimpin tidak dapatdikatakan berkarisma kecuali para pengikutnya telah memvalidasi klaim tersebut (Bass, 1988, pp. 40-77).

Hasil temuan lainnya menyatakan bahwa kepala PAUD memiliki wibawa dihadapan pendidik. Hal ini sesuai pendapat Wahyusumidjo bahwa istilah karisma sama dengan kewibawan pribadi (Wahyusumidjo, 2011, p. 35). Pentingnya rasa hormat tinggi pada kepemimpinan transformaisonal menjadi rujukan pendidik untuk mau mengikuti apa yang dipengaruhi dan dimintkan pemimpin untuk meraih tujuan (Mohammad Muchlis, 2007). Rasa hormat yang dimiliki oleh seseorang dalam pandangan Lickona dapat dilihat dari penghormatan yang diberikan terhadap sesuatu yang dimiliki, dimana ketika seseorang memiliki rasa hormat, ia akan merasa apapun yang ada merupakan bagian dirinya (Lickona, 1992, p. 25).

\section{Inspirational Motivation (Motivasi Inspirasi)}

Berdasarkan pengumpulan data penelusuran peneliti, Kepala TK Islam Al Irsyad dan Kepala TK Islamiyah Rahmatan Lil'alamin senantiasa berperilaku untuk melakukan transformasi dalam peningkatan mutu pendidik melalui hal-hal yang menginspirasi dan memotivasi pendidik. Kedua kepala PAUD mengingatkan dan mendorong pendidik untuk melakukan perubahan yang bermanfaat dan memiliki pengaruh baik. Membantu pendidik apabila mengalami kesulitan yang menghambat kemajuan pendidik, dan terus mengingatkan mengenai tujuan, visi dan misi lembaga.

Temuan ini sesuai dengan perndapat Burns bahwa bahwa kepemimpinan transformasional sebagai proses pengaruh sosial, di mana para pemimpin dan pengikut terlibat dalam proses bersama untuk meningkatkan satu sama lain ke tingkat moralitas dan motivasi yang lebih tinggi (Burns, 1978). Prilaku kepala PAUD yang memberikan motivasi pada pendidik untuk terus berupaya meningkatkan kinerja dengan standar-standar yang menjadi tugas dan pokok pendidik memiliki pengaruh tersendiri terhadap tercapainya kualitas pendidik (Anwar \& Umar, 2021). Temuan penelitian ini mendukung hasil penelitian tentang kepemimpinan transformasional dalam meningkatkan mutu pendidik PAUD bahwa pemimpin yang memotivasi secara aktif akan meningkatkan kinerja anggotanya (Nurmiyanti \& Candra, 2019).

Selain itu, hasil penelitian pada kedua lembaga, kepala PAUD memberikan motivasi dalam bentuk memberikan wejangan atau pengetahuan yang dapat menginspirasi anggota dengan lebih menekankan pada nilai-nilai dan kesetiaan. Temuan ini senada dengan pernyataan bahwa inspirasi motivasi digunakan sebagai pendekatan untuk mempengaruhi dan menggerakkan anggota organisasi pendidikan (Setiawan \& Muhith, 2013, p. 164). Motivasi kerja pendidik merupakan kondisi yang membuat guru mempunyai kemauan atau 
kebutuhan untuk mencapai tujuan tertentu melalui pelaksanaan suatu tugas. Motivasi akan memberikan energi untuk bekerja dan mengarahkan segenap aktivitasnya selama bekerja, dan menyebabkan seorang guru mengetahui adanya tujuan yang relevan antara tujuan organisasi dan mencapai tujuan pribadinya (Anwar, 2019).

Kepemimpinan transformasional berprilaku yang dapat menimbulkan motivasi untuk untuk pencapaian tujuan kelompok (Marginingsih, 2016). Pernyataan ini sesuai dengan hasil temuan pada kedua lokasi penelitian bahwa senantiasa memberikan motivasi melalui pemberian tugas- tugas yang kompleks, menantang, inisiatif, berisiko sehinggga anggota menjadi lebih bertanggung jawab dan tekun. Selain itu Kepala TK Islam Al Irsyad dan TK Islamiyah Rahmatan Lil'alamin memotivasi pendidik tanpa mengintimidasi atau otoriter. Hal ini sejalan penelitian terdahulu bahwa kepemimpinan Nabi Muhammad SAW menyatukan umatnya melalui persuasive, approach, diplomasi, dialog konsensus, dan rekonsoliasi bukan dengan cara security approach, intimidasi, dan pemaksaan (Sakdiah, 2016).

Apek inspirational motivation pada kepemimpinan transformasional kepala PAUD di kedua lembaga untuk meningkatkan mutu pendidik melalui hasil peningkatan integritas kerjasama antar warga sekolah, menjamin efektivitas dan efisiensi kerjasama antar anggota sekolah dan meningkatkan partisipasi aktif dan tanggungjawab sosial pada sleuruh anggota. Kartono menyimpulkan bahwa pemberian motivasi kepemimpinan sebagai upaya meningkatkan produktivitas seluruh warga sekolah (Kartono, 2014, p. 43).

\section{Intellectual Stimulation (Stimulasi Intelektual)}

Berdasarkan penelusuran yang telah peneliti lakukan, Intellectual stimulation menjadi karakteristik kepala TK Islam Al Irsyad dan TK Islamiyah Rahmatan Lil'alamin. Hasil penelitian menghasilkan bahwa kepala PAUD di kedua lembaga menstimulasi pendidik melalui rangsangan untuk melahirkan kreativitas pada pembelajaran di kelas. Menstimulasi intelektual pendidik mengadakan kegiatan pengembangan menambah wawasan pendidik seperti pelatihan dan pendidik, seminar, worksop, dan kegiatan peningkatan kompetensi lainnya. Pendidik PAUD menjadi pihak yang langsung berinteraksi dengan peserta didik sehingga harus senantiasa memiliki semangat dalam belajar, berkarya, dan berprestasi. Mengembangkan intelektual pendidik sebagai bagian dari bentuk keprofesionalan pendidik.

Kepemimpinan trasnformasional kepala PAUD untuk meningkatkan mutu pendidik mestimulasi pendidik melalui pengembangan empat kompetensi dasar pendidik PAUD yaitu kompetensi padagogik, kepribadian, professional, dan sosial. Bagaimanapun, sikap kepemimpinan yang ditunjukkan oleh kepala PAUD dalam bentuk inisiatif, kreatif mandiri dan profesional tentunya akan menstimulir pendidik untuk meneladani perilaku kepala sekolah. Pendidik akan semakin berhasrat, memiliki semangat kerja yang tinggi serta berpikir positif dalam menyelenggarakan proses pembelajaran yang menjadi tanggung jawab profesionalnya (Anwar, 2021).

Temuan ini dikuatkan hasil penelitian Dong I. Jung yang menyatakan bahwa stimulasi intelektual terlihat (Jung, 2001). Melalui stimulasi intelektual bawahan, metode baru untuk mencapai misi organisasi dieksplorasi. Menurut Berson dan Avolio, stimulasi intelektual menjadi tantangan pengikut untuk menerima solusi inovatif untuk sebuah permasalahan yang harus dihadapi (Berson \& Avolio, 2004).

Islam mengajarkan bahwa manusia untuk selalu berupaya melakukan inovasi di setiap kehidupannya. Rasullullah Saw bersabda"Barangsiapa yang menunjuki kepada kebaikan maka dia akan mendapatkan pahala seperti pahala orang yang mengerjakannya" (HR. Muslim no. 1893).Al Qur'an secara eksplisit maupun implisit membicarakan tentang kebebasan manusia untuk menentukan sendiri perbuatannya yang bersifat ikhtiyariyyah, yakni perbuatan yang dinisbatkan kepada manusia dan menjadi tanggung jawabnya, karena kemampuan yang dimilikinya untuk melakukan atau meninggalkannya(Machasin, 1996, p. 31) 
Stimulasi intelektual dimaknai sebagai sebuah prilaku yang berupaya menumbuhkan kesadaran pengikut dengan berbagai komplesitas yang terjadi pada indovidu dan organisasi. Perilaku pemimpin tersebut berdampak timbulnya kesadaran seluruh anggota dalam upaya encapai visi, misi dan tujuan organisasi. Pemberian stimulasi atau rangsangan intelektual oleh kepala TK Islam Al Irsyad dan TK Islamiyah Rahmatan Lil'alamin dengan pembimbingan dalam penyelesaian tugas-tugas guru. Dalam hal ini upaya yang dapat dilakukan oleh kepala PAUD adalah melakukan supervisi dengan tujuan peningkatan kapasitas pendidik dalam mengembangan intelektualitas guru atau kompetensinya. Temuan ini sesuai dengan fungsi daripada kepala sekolah sebagai manajer yang bertugas memastikan bahwa pembelajaran berlangsung efektif, dan mengukur hasil yang dicapai untuk dijadikan acuan bagi perbaikanperbaikan mutu pada tahap selanjutnya (Fadhli, 2016).

\section{Individualized Consideration (Perhatian Individu)}

Hasil penelusuran pada penelitia ini pada sspek individualized consideration yang dilakukan melalui kepemimpinan transformasional kepala PAUD untuk meningkatkan mutu pendidik berdasarkan haisl penelusuran melalui pemberian perhatian secara personal kepada pendidik. Kepala PAUD memperhatikan apa yang menjadi hambatan dan keterbatasan yang dimiliki pendidik. Mengajak pendidik berdiskusi, bermusyawarah. Berdasarkan hasil wawancara kepada pendidikn selaku informan didapati haisl bahwa perhatian kepala PAUD menyebabkan pendidk merasa diperhatikan dan merasa dihormati. Hasil penelitian sejalan dengan penelitian terdahulu bahwa kepemimpinan transformasional menyebabkan pengikut merasa dipercaya, dihormati dan disukai dengan tidak melalui hukuman dan ganjaran (Kouzes \& Posner, 2017).

Temuan lainnya menghasilkan bahwa adanya karakteristik perhatian individu oleh kedua kepala PAUD melalui perenungan, pertimbangan dengan proses berfikir serta indentifikasi kebutuhan para pendidik di sekolah. Temuan ini sejalan dengan penelitian mengenai dampak kepemimpinan transformasional terhadap control system organisasi yang menyatakan bahwa pemimpin transformasional menggunakan pertimbangan individual secara signifikan, yang pada gilirannya berkontribusi pada bawahan untuk mencapai potensi secara maksimal (Nguyen et al., 2016).

Temuan pada aspek individualized consideration pada TK Islam Al Irsyad dan TK Islamiyah Rahmatan Lil'alamin menghasilkan dampak baik yaitu kedekatan secara emosional antar kepala PAUD dengan pendidik. Hal tersebut sesuai dengan hasil penelitian yang menyatakan bahwa pertimbangan individual, pemimpin membangun hubungan satu-ke-satu dengan pengikutnya, dan memahami serta mempertimbangkan kebutuhan, keterampilan, dan aspirasi mereka yang berbeda (Gumusluoglu \& Ilsev, 2009).

Berdasarkan hasil penelusuran diketahui bahwa kepemimpinan transformasional kepala TK Islam Al Irsyad dan Kepala TK Islamiyah Rahmatan Lil'alamin memperhatikan kebutuhan pendidik dengan mengidentifikasi kebutuhan serta menganalisis skill sumber daya pendidik. Aspek pada perhatian individu menurut Sosik dan Avolion merupakan pemimpin dengan memperhatikan perbedaan individu dalam kebutuhan bawahan untuk tumbuh dan berkembang (Sosik, Kahai, \& Avolio, 1998). Perhatian individu dimaknai sebagai perilaku pemimpin transformatif dalam merefleksi diri dalam keberlangsungan dan keberlanjutan organisasi pendidikan yang dipimpinnya. Upaya mencapai tujuan tersebut melalui identifikasi kebutuhan bawahan dengan memberikan pembinaan, pembimbingan serta pelatihan melalui pengendalian kapasitas, pendelegasian, pemberian respon dan penghargaan terhadap hasil kinerja yang dicapai oleh pengikut.

\section{SIMPULAN}

Meningkatnya mutu pendidik yang terjadi di TK Islam Al Irsyad Madiun dan TK Islamiyah Rahmatan Lil'alamin Kota Madiun sebagai bagian dari keberhasilan kepemimpinan transformasional kepala PAUD berdasarkan empat aspek. Aspek charisma berupa 
keteladanan dan mampu menularkan uswah dalam organisasi pendidik dan adanya pengakuan. Aspek motivasi inspirasi melalui hasil peningkatan integritas kerjasama antar warga sekolah, menjamin efektivitas, efisiensi kerjasama dan meningkatkan partisipasi aktif dan tanggungjawab sosial. Aspek stimulasi intelektual pendidik melalui pengembangan empat kompetensi dasar pendidik PAUD dan sikap kepemimpinan dalam bentuk inisiatif, kreatif mandiri dan professional. Aspek perhatian individu dengan mengidentifikasi kebutuhan yang sedang diperlukan oleh pendidik, kemudian merespon, menganalisis kebutuhan, pemberian pembinaan, pembimbingan dan pelatihan.

\section{UCAPAN TERIMAKASIH}

Peneliti ucapkan terimakasih kepada TK Islam Al Irsyad Madiun dan TK Islamiyah Rahmatan Lil'alamin yang telah banyak membantu peneliti dalam menyelesaikan penulisan penelitian ini. Peneliti juga mengucapkan banyak terimaksih kepada pihak-pihak yang telah banyak membantu sehingga penelitian ini dapat terlaksana dengan lancar.

\section{DAFTAR PUSTAKA}

Anwar, R. N. (2019). Motivasi Belajar Baca Tulis Al Quran Pada Ibu Rumah Tangga Di TPQ Anwarul Qulub Sidorejo. Prosiding Seminar Nasional \& Call Paper Psikologi Pendidikan, (April), 162-166. Malang: Universitas Negeri Malang.

Anwar, R. N. (2021). Management of Islamic Religious Education Learning in Children with Special Needs. Jurnal Obsesi: Jurnal Pendidikan Anak Usia Dini, 6(1), 539-548. https://doi.org/10.31004/obsesi.v6i1.971

Anwar, R. N., \& Alfina, A. (2019a). Kepemimpinan Kepala Sekolah Dalam Pengembangan Profesionalisme Guru Di TK IT Nur Al Izhar Kebonsari. Conference on Research \& Community Services, 51-56. Jombang: STKIP PGRI Jombang.

Anwar, R. N., \& Alfina, A. (2019b). Manajemen Sumber Daya Manusia Di TK IT Nur Al Izhar Kebonsari (Studi Kasus Pengembangan Guru). Thufuli: Jurnal Pendidikan Islam Anak Usia Dini, I(2), 1-12. https:/ / doi.org/10.33474/thufuli.v1i2.4876

Anwar, R. N., \& Umar, M. (2021). Motivasi Guru Dalam Bekerja Perspektif Islam. Paedagoria: Jurnal Kajian, Penelitian, Dan Pengembangan Kependidikan, 12(2), 296-302.

Anwar, R. N., \& Zaenullah. (2020). Perencanaan Pembelajaran Pendidikan Agama Islam Pada Anak Berkebutuhan Khusus. Jurnal Care, 8(1), 56-66.

Aqib, Z. (2017). Upaya Penjaminan Mutu Pendidikan Melalui Akreditasi Sekolah. Jurnal Annaba, 3(2).

Bass, B. M. (1985). Leadership and Performance Beyond Expectations. New York: Free Press.

Bass, B. M. (1988). Evolving Perspectives On Charismatic Leadership. San Fransisco: JoseyBass.

Bass, B. M. (1990). Bass \& Stogdill's Handbook of Leadership: Theory, Research, and Managerial Application. New York: Free Press.

Bass, B. M., \& Avolio, B. J. (1993). Transformational Leadership And Organizational Culture. Spring, 17(1), 112-121.

Berson, Y., \& Avolio, B. J. (2004). Transformational Leadership And The Dissemination Of Organizational Goals: A Case Study Of A Telecommunication Firm. Leadership Quarterly, 15(5), 625-646. https:// doi.org/10.1016/j.leaqua.2004.07.003

Boyd, M. (2013). " I love My Work But ..." The Professionalization of Early Childhood Education. The Qualitative Report, 18(36), 1-20.

Brata, D. P. N. (2017). Kepemimpinan Transformasional Kepala Sekolah Dalam Mengimplementasikan Pendidikan Karakter (Studi Multisitus di SMKN 1 Kota Jombang, SMKN 1 Kota Mojokerto, dan SMKN Sooko Kabupaten Mojokerto), Disertasi Doktor. Universitas Negeri Malang.

Burns, J. M. (1978). Leadership. New York: Free Press. 
Cikita, N. P. (2018). Studi Kualifikasi Akademik Guru Taman Kanak-Kanak Se-Kecamatan Srandakan Kabupaten Bantul. Jurnal Pendidikan Anak Usia Dini, 8(7), 658-667.

Eyal, O., \& Roth, G. (2011). Principals' leadership and Teachers' Motivation Self-Determination Theory Analysis. Journal of Educational Administration, 49(3), 256-275. https://doi.org/10.1108/09578231111129055

Fadhli, M. (2016). Kepemimpinan Kepala Sekolah Yang Efektif Dalam Menciptakan Sekolah Efektif. Jurnal Tarbiyah, 23(1), 23-44.

Gumusluoglu, L., \& Ilsev, A. (2009). Transformational Leadership, Creativity, And Organizational Innovation. Journal of Business Research, 62(4), 461-473. https://doi.org/10.1016/i.jbusres.2007.07.032

Hafidz, A. Y. N. (2019). Kepemimpinan Transformasional Kepala Sekolah Dasar Berciri Agama Islam di Kota Banjarmasin (Studi Multi Kasus pada Sekolah Dasar Islam Terpadu Ukhuwah, Sekolah Dasar Muhammadiyah 10 dan Sekolah Dasar Islam Sabilal Muhtadin), Disertasi Doktor. Universitas Negeri Malang.

Herminingsih, A. (2011). Pengaruh Kepemimpinan Transformasional Terhadap Budaya Organisasi. Jurnal Ilmiah Ekonomi Manajemen Dan Kewirausahaan "Optimal," 5(1), 22-37.

Hoy, W. K., \& Miskey, C. G. (2013). Educational Administration: Theory, Research, and Practice. New York: MCGraw Hill.

Istiqomah, L. (2017). Tiga Pilar Kebijakan Pemerintah Dalam Pembinaan Paud. Golden Age: Jurnal Ilmiah Tumbuh Kembang Anak Usia Dini, 1(2), 57-66. https://doi.org/10.14421/iga.2016.12-05

Jung, D. I. (2001). Transformational And Transactional Leadership And Their Effects On Creativity In Groups. Creativity Research Journal, 13(2), 185-195. https://doi.org/10.1207/S15326934CRJ1302_6

Kartono, K. (2014). Pemimpin dan Kepemimpinan: Aapakah Kepemimpinan Abnormal itu? Jakarta: Rajawali Press.

Kemendikbud. Peraturan Menteri Pendidikan dan Kebudayaan Republik Indonesia Nomor 146 Tahun 2014 Tentang Kurikukum 2013 Pendidikan Anak Usia Dini. , Kemendikbud Pendidikan Anak Usia Dini § (2014).

Kosasih, A. (2017). Pengaruh Kepemimpinan Transformasional, Budaya Organisasi Dan Motivasi Kerja Pegawai Terhadap Kepuasan Kerja Pegawai Serta Implikasinya Pada Kinerja Pegawai PDAM Di Provinsi Banten, Disertasi Doktor. Universitas Pasundan. https://doi.org/10.31000/jgcs.v1i2.442

Kouzes, J. M., \& Posner, B. Z. (2017). The Leadership Challenge: How to Make Extraordinary Things Happen in Organizations (6th ed.). Hoboken: Wiley.

Lickona, T. (1992). Educating for Character How Our Schools and Responsibility. New York: Bantam Books.

Machasin. (1996). Menyelami Kebebasan Manusia. Yogyakarta: Pustaka Pelajar.

Marginingsih, R. (2016). Kepemimpinan Karismatik Sebagai Employer Branding. Jurnal Bisnis Darmajaya, 2(2), 32-51.

Maris, I. S., Komariah, A., \& Abubakar. (2016). Kepemimpinan Transformasional Kepala Sekolah, Kinerja Guru Dan Mutu Sekolah. Jurnal Administrasi Pendidikan, XXIII(2), 173-188.

Maris, I. S., Komariah, A., \& Bakar, A. (2016). Kepemimpinan Transformasional Kepala Sekolah, Kinerja Guru Dan Mutu Sekolah. Jurnal Administrasi Pendidikan, 23(2).

Menteri Pendidikan dan Kebudayaan. (2014). Permendikbud No 137 Standar Nasional Pendidikan Anak Usia Dini (No. 137). Jakarta.

Mohammad Muchlis, S. (2007). Fitrah; Konsep Dan Pengembangannya Dalam Pendidikan Islam. Tadrîs, 2(2), 236-249.

Muhardi. (2005). Kontribusi Pendidikan Dalam Meningkatkan Kualitas Bangsa Indonesia. Mimbar, XX(4), 478-492. Retrieved from https://doi.org/10.29313/mimbar.v20i4.153 
Mulyasa, E. (2012). Manajemen PAUD. Bandung: PT Rosdakarya.

Nguyen, T. T., Mia, L., Winata, L., \& Chong, V. K. (2016). Effect Of TransformationalLeadership Style And Management Control System On Managerial Performance. Journal of Business Research. https://doi.org/10.1016/j.jbusres.2016.08.018

Nurhaya. (2017). Kepemimpinan Kepala Sekolah Dalam Meningkatkan Mutu Pendidikan Di SDN 4 Sungai Nilam Jawai. Jurnal Pendidikan Dan Pembelajaran Khatulistiwa, 6(11), 1-10. https:// doi.org/10.31851/jmksp.v1i2.1012

Nurmiyanti, L., \& Candra, B. Y. (2019). Kepemimpinan Transformasional Dalam Peningkatan Mutu Pendidikan Anak Usia Dini. Al-Tanzim: Jurnal Manajemen Pendidikan Islam, 3(2), 13-24. https://doi.org/10.33650/al-tanzim.v3i2.646

Priansa, D. . (2014). Kinerja dan Profesionalisme Guru Fokus pada Peningkatan Kualitas Pendidikan, Sekolah dan Pembelajaran. Bandung: Alfabeta.

Qomar, M. (2007). Manajemen Pendidikan Islam. Jakarta: Penerbit Erlangga.

Saifulloh, S. (2010). Etos Kerja Dalam Perspektif Islam. Jurnal Sosial Humaniora, 3(1), 54-69. https:// doi.org/10.12962/j24433527.v3i1.654

Sakdiah. (2016). Karakteristik Kepemimpinan Dalam Islam ( Kajian Historis Filosofis ) SifatSifat Rasulullah. Jurnal Al-Bayan, 22(33), 29-49.

Saleh, A. R., \& Utomo, H. (2018). Pengaruh Disiplin Kerja, Motivasi Kerja, Etos Kerja Dan Lingkungan Kerja Terhadap Produktivitas Kerja Karyawan Bagian Produksi Di Pt. Inko Java Semarang. Among Makarti, 11(1), 28-50. https:// doi.org/10.52353/ama.v11i1.160

Setiawan, B. A., \& Muhith, A. (2013). Transformational Leadership: Ilustrasi di Bidang Organisasi Pendidikan. Jakarta: PT. Grafindo Persada.

Smith, K., Hodson, E., \& Brown, T. (2013). Teacher Educator Changing Perceptions of Theory. Educational Action Research, 21(2), 237-252. https:// doi.org/10.1080/09650792.2013.789723

Sosik, J. J., Kahai, S. S., \& Avolio, B. J. (1998). Transformational Leadership And Dimensions Of Creativity: Motivating Idea Generation In Computer-Mediated Groups. Creativity Research Journal, 11(2), 111-121. https:// doi.org/10.1207/s15326934crj1102_3

Sumual, T. E. M. (2019). Pengaruh Kompetensi Kepemimpinan, Budaya Organisasi terhadap Kinerja Pegawai di Universitas Negeri Manado. Jurnal Mimbar, 31(1), 71-80. https:// doi.org/10.29313/mimbar.v31i1.1296

Wahyusumidjo. (2011). Kepemimpian Kepala Sekolah: Tinjauan Teoritik Dan Permasalahannya. Jakarta: Rajawali Press.

Wang, H. J., Demerouti, E., \& Le Blanc, P. (2017). Transformational Leadership, Adaptability, and Job Crafting: The Moderating Role of Organizational Identification. Journal of Vocational Behavior, 100, 185-195. https:// doi.org/10.1016/j.jvb.2017.03.009

Yunus, S. (2017, November 24). Mengkritisi Kompetensi Guru. Detik News. 